\title{
Differences in the ability to suppress interferon $\beta$ production between allele A and allele B NS1 proteins from $\mathrm{H} 10$ influenza $A$ viruses
}

\author{
Siamak Zohari ${ }^{1,2^{*}}$, Muhammad Munir ${ }^{1}$, Giorgi Metreveli ${ }^{1}$, Sándor Belák ${ }^{1,2}$, Mikael Berg ${ }^{1}$
}

\begin{abstract}
Background: In our previous study concerning the genetic relationship among $\mathrm{H} 10$ avian influenza viruses with different pathogenicity in mink (Mustela vison), we found that these differences were related to amino acid variations in the NS1 protein. In this study, we extend our previous work to further investigate the effect of the NS1 from different gene pools on type I IFN promoter activity, the production of IFN- $\beta$, as well as the expression of the IFN- $\beta$ mRNA in response to poly I:C.

Results: Using a model system, we first demonstrated that NS1 from A/mink/Sweden/84 (H10N4) (allele A) could suppress an interferon-stimulated response element (ISRE) reporter system to about 85\%. The other NS1 (allele B), from A/chicken/Germany/N/49 (H10N7), was also able to suppress the reporter system, but only to about 20\%. The differences in the abilities of the two NS1s from different alleles to suppress the ISRE reporter system were clearly reflected by the protein and mRNA expressions of IFN- $\beta$ as shown by ELISA and RT-PCR assays.

Conclusions: These studies reveal that different non-structural protein 1 (NS1) of influenza viruses, one from allele $A$ and another from allele $B$, show different abilities to suppress the type I interferon $\beta$ expression. It has been hypothesised that some of the differences in the different abilities of the alleles to suppress ISRE were because of the interactions and inhibitions at later stages from the IFN receptor, such as the JAK/STAT pathway. This might reflect the additional effects of the immune evasion potential of different NS1s.
\end{abstract}

\section{Background}

Type I interferons (IFNs) play an essential role in both the innate immune response and the induction of adaptive immunity against viral infections. Viral infections trigger the production of type I IFNs (IFN- $\alpha / \beta)[1,2]$, which leads to the activation of several hundred IFN-stimulated genes (ISGs). These genes encode a variety of antiviral proteins and cytokines, leading to the protection of the host from further viral infections [3,4].

The main viral sensors in most mammalian nucleated cells are RNA helicases, retinoic acid-inducible gene I (RIG-I) and melanoma differentiation-associated protein 5 (MDA-5), which recognises viral single-stranded RNA (ssRNA) and double-stranded RNA (dsRNA) [1,5-9].

\footnotetext{
* Correspondence: siamak.zohari@sva.se

'Swedish University of Agricultural Sciences (SLU), Department of Biomedical Sciences and Veterinary Public Health, Section of Virology, SLU, Ulls väg 2B, SE-751 89 Uppsala, Sweden

Full list of author information is available at the end of the article
}

Many cells also recognise viral dsRNA through Toll-like receptor 3 (TLR3) [1,10]. The binding of virus-derived nucleic acids to RIG-I, MDA-5 or TLR3 results in a coordinated activation of the transcription factors nuclear factor kappa B (NF- $\kappa \mathrm{B})$ and interferon regulatory factor 3 (IRF-3), leading to IFN- $\beta$ production in mammals $[6,7,10]$.

Although a variety of cellular signalling has been evolved in host cells for detecting and responding to viral infection, most viruses possess mechanisms to evade these host immune responses to various degrees $[7,11]$. For example, many viruses have developed a multitude of mechanisms to evade the IFN response by either blocking IFN synthesis or interfering with the functions of IFN [12].

In the case of influenza A viruses, the non-structural gene (NS) has been shown to be responsible for viral anti-IFN activities [13-16]. The NS gene of influenza A viruses encodes for two proteins [17]. The first is

\section{Biomed Central}


through the translation of unspliced mRNA, which encodes a protein of $26 \mathrm{kDa}$ known as non-structural protein 1 (NS1). The second is a $14 \mathrm{kDa}$ nuclear export protein (NEP, formerly called NS2) translated from spliced mRNA [18].

The NS1 protein antagonises both the induction of IFN- $\beta[19,20]$ and the activity of several IFN-induced proteins with antiviral activities such as protein kinase $R$ (PKR) and 2'-5'oligoadenylate synthetase (OAS) [21-23].

The NS gene can be classified into separate gene pools, termed alleles A and B $[24,25]$. Between allele A and $\mathrm{B}, 63-68 \%$ nucleotide identity and $66-70 \%$ amino acid identity was found between the NS1 proteins. The NS allele A is more common and is the only subtype found in mammalian-adapted isolates. In a comparison between amino acid sequence of avian allele A and B viruses with an amino acid sequence of human viruses, six amino acid motifs, or signatures, were found between human and avian allele A viruses, and 35 signatures between human and allele B viruses, indicating that allele $\mathrm{B}$ viruses are more distinct from mammalian origin viruses [26]. This suggests that the adaptation of NS1 plays an important role in the pathogenicity of avian influenza viruses in mammalian species.

In our previous study concerning the genetic relationship among $\mathrm{H} 10$ avian influenza viruses with different pathogenicity in mink (Mustela vison), we found that these differences were related to amino acid variations in the NS1 protein. We demonstrated that in a model system using polyinosinic-polycytidylic acid (poly I:C)stimulated mink lung cells, the NS1 protein of influenza A virus isolated from mink (A/mink/Sweden/84 (H10N4)) down regulated type I IFN promoter activity to a greater extent than the NS1 protein of prototype $\mathrm{H} 10$ virus (known as virus/N (A/chicken/Germany/N/49 (H10N7)) [27].

In this study, we extend our previous work to further investigate the effect of the NS1 from different gene pools on type I IFN promoter activity, the production of IFN- $\beta$, as well as the expression of the IFN- $\beta$ mRNA in response to poly I:C.

\section{Results}

\section{Activation of IFN- $\beta$ promoter}

First, we studied the ability of NS1 from "mink/84" and "chicken/49" to inhibit the induction of transcription of the IFN- $\beta$ gene, using the model system ISRE-Luciferase and Poly I:C stimulation. This reporter system relies on expression of IFN and the subsequent signalling from the IFN- $\alpha / \beta$ receptor leading to expression from the ISRE reporter gene (luciferase). Although both NS1 from "mink/84" and "chicken/49" showed a significant suppressive effect on the luciferase activity, it was considerably stronger in cells transfected with "mink/84"

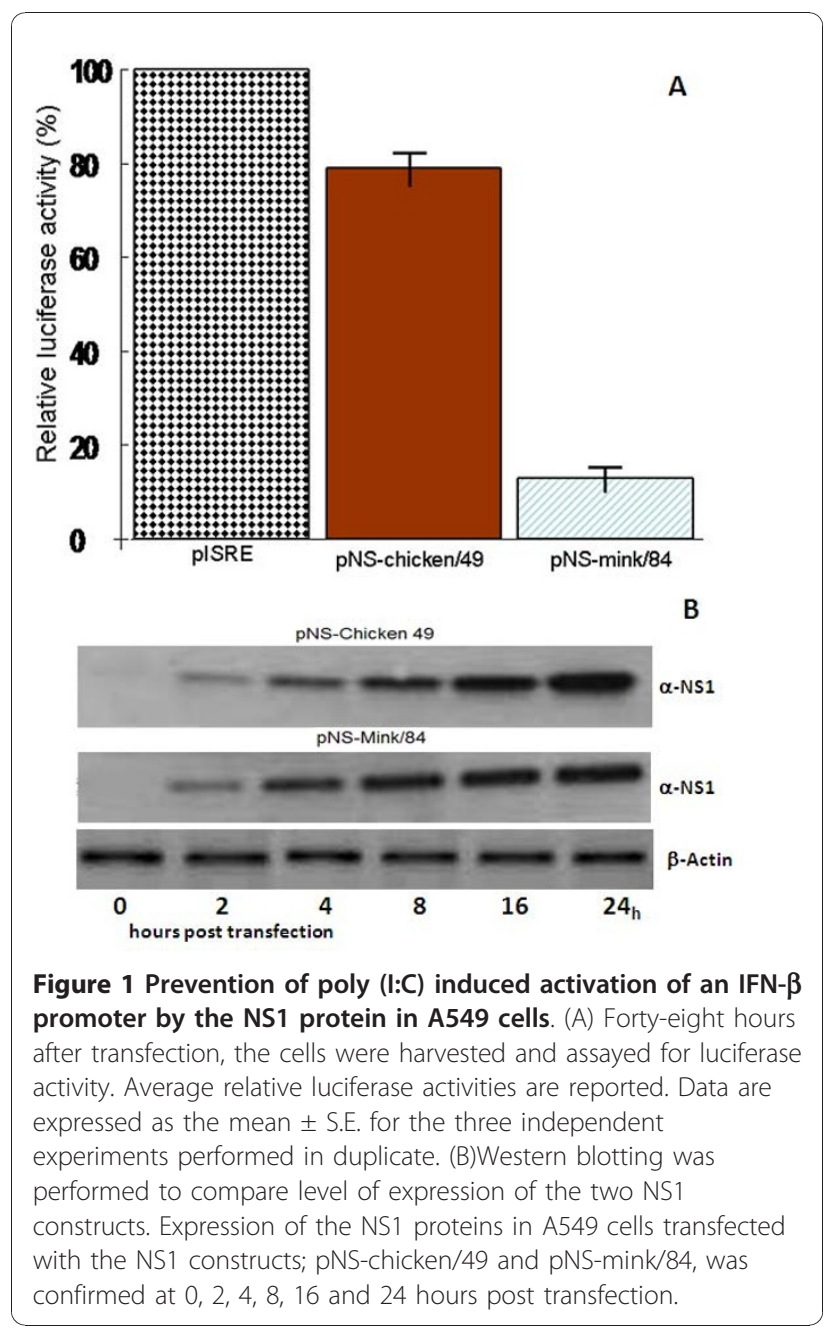

with an average of 6.8 fold decrease (85.3\%) in A549 cells (Figure 1A), compared with "chicken/49", that on average produced a $20.8 \%$ decrease in A549 cells.

\section{Expression of NS1 proteins in A549 cells}

To find out whether the difference in inhibition of IFN$\beta$ promoter is duo to difference in- or insufficient expression of the NS1 proteins in A549 cells, the level of expressed NS1 proteins was confirmed by western blot analysis. The cells were lysed at $0,2,4,8,16$ and 24 hours post transfection and western blotting was performed. The NS1 proteins from both constructs were expressed in high quantity and the level of allele A NS1 was comparable to NS1 protein of allele B (Figure 1B). The western blotting showed that the expressed protein from both "mink/84" and "chicken/49" was homogenously accumulated in A549 cells and there was no notable difference between alleles in term of NS1 production (Figure 1B). Thus, the results indicated that the difference in IFN- $\beta$ induction in the presence of allele B 
NS1 protein was not due to difference in allele B NS1 protein expression and accumulation in the cells.

At this point it was not clear if this result corresponded to differences in the ability to downregulate IFN production, or that the signalling pathway leading to ISRE transcription is influenced, or both. To sort out this, IFN protein production was measured by an ELISA.

\section{IFN- $\beta$ production}

The IFN- $\beta$ protein was detected in the cell medium of the control cells after a lag of 2 to 4 hours after poly I:C stimulation, followed by the linear accumulation of IFN$\beta$ in the cell culture supernatant. The peak yields for control cells were reached about 16 to 24 hours poststimulation (Figure 2A). Although low levels of IFN- $\beta$ were secreted by cells transfected with different NS1s, significant differences were observed between these NS1s. Those cells expressing the NS1 protein of "mink/ 84 " virus were weak producers of IFN- $\beta$, with at least 10 times lower levels of IFN- $\beta$ secreted in the cell culture supernatant than the control cells. In these cells IFN $-\beta$ secreted to the supernatant reached the maximum yield 8 hours post-stimulation and declined rapidly to a low level for the rest of the experiment. By contrast, cells expressing the NS1 protein of "chicken/49" were better producers of IFN- $\beta$ with the profile lower but similar to that observed with the control cells (Figure 2A). This indicates that NS1, in this system, suppresses IFN protein production rather than the signalling from the IFN receptor.

\section{Expression of IFN- $\beta$ in response to poly I:C}

To determine whether the reduction of IFN- $\beta$ production was caused by the suppression of the expression of the IFN- $\beta$ gene, we compared gene expression kinetics in A549 cells stimulated with poly I:C in the presence or absence of different NS1 proteins.

In the control cells, IFN- $\beta$ mRNA was detected in increased amounts during the entire period of the experiment (Figure 2B). The same profile was observed in the cells expressing the NS gene of "chicken/49 " (Figure 2C). Transcript levels in the control cells were significantly increased 2 to 4 hours post-stimulation, reaching a plateau at the end of the experiment. Four hours after stimulation, the NS1 protein of the "mink/ 84" effectively suppressed IFN- $\beta$ gene transcription in A54.9 cells (Figure 2D). The activation of the IFN $-\beta$ gene expression in cells transfected with plasmids carrying the NS gene of "chicken/49" resulted in increased levels of IFN $-\beta$ mRNA showing the same trend similar to the control cells.

The RT-PCR analysis of the INF- $\beta$ mRNA presented in the stimulated A549 cells expressing NS1 of "mink/ 84" or "chicken/49" confirmed that the NS1 protein of

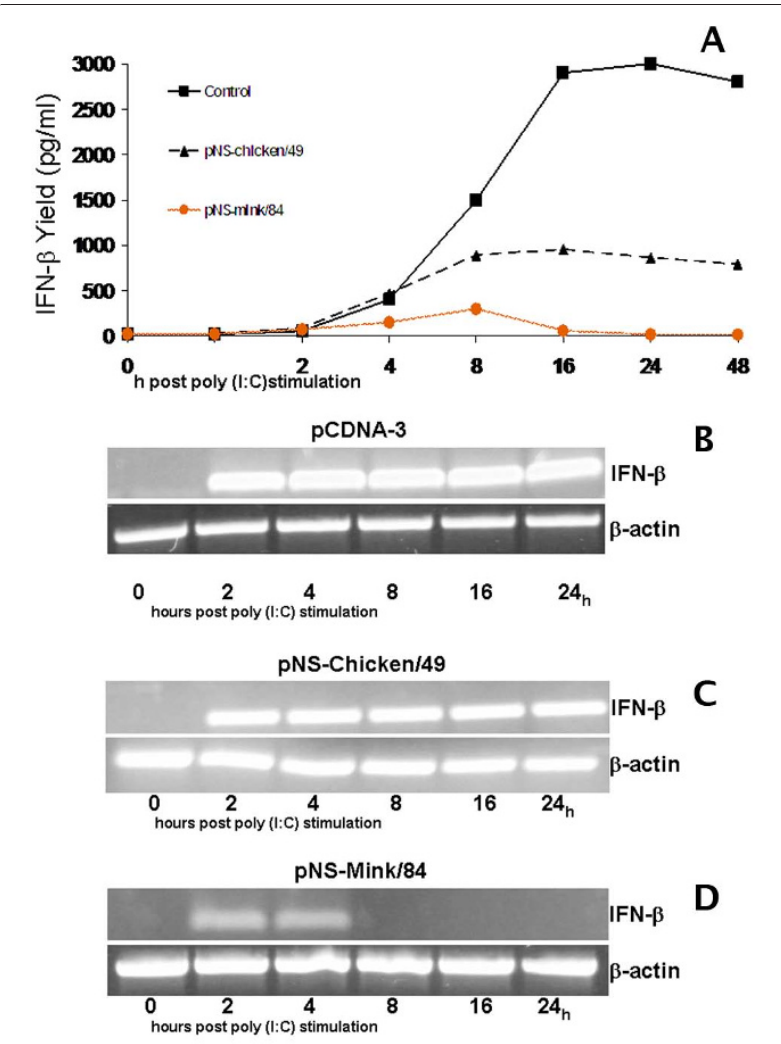

Figure 2 IFN- $\beta$ release in the supernatant and expression of IFN- $\beta$ m-RNA in human A549 epithelial cells in response to poly I:C challenge at the presence of different NS1 proteins. (A) The concentration of IFN- $\beta$ in A549 cell supernatants was assayed. Cell were transfected with plasmids containing either the NS gene of "mink/84" or "chicken/49" virus or was mock treated, 24 hours later cells were stimulated with $5 \mu \mathrm{g} / \mathrm{ml}$ of poly I:C. The cell supernatants were collected at $0,2,4,8,16,24$ and 48 hours postpoly I:C stimulations. Expression of IFN- $\beta$ m-RNA in A549 cells in response to poly $\mathrm{I}: \mathrm{C}$ challenge at the presence of different NS1 proteins. A549 cells were transfected with (B) empty pCDNA-3 vector, (C) pNS-mink/84 and (D) pNS-chicken/49 respectively, $24 \mathrm{~h}$ later cell were treated with $5 \mathrm{\mu g} / \mathrm{ml}$ poly (I:C) for indicated time. Data are expressed as the mean value for the three independent experiments performed in duplicate.

"mink/84" effectively suppressed IFN- $\beta$ gene transcription in A549 cells, indicating that the main target of the "mink/84" NS1 is the induction of IFN.

\section{Discussion}

One of the main strategies of the influenza A viruses to avoid host immune responses is to inhibit IFN- $\alpha / \beta$ expression or signalling to the neighbouring cells, which induce their antiviral state by the stimulation of transcription from the ISRE promoter-containing genes [28]. The viral NS1 of influenza A viruses is known to be an important regulator of innate immunity on many levels [13-16]. The NS1 inhibits host immune responses through two functional domains: an N-terminal RNA 
binding domain and a C-terminal effector domain [19]. The effector domain interacts with proteins involved in the 3'-end cellular mRNA processing, inhibits mRNA export and pre-mRNA splicing of host cell transcripts and interacts with components of the nuclear pore complex as well as the mRNA export machinery [29-34]. The N-terminal RNA binding domain binds to both single- and double-stranded RNA that might inhibit the activation and/or signalling of antiviral proteins, such as RIG-I, PKR, OAS/RNase L, activators of mitogenactivated protein kinase and transcription factors involved in type I IFN and inflammatory cytokine signalling [20,22,23,35-37].

Our previous study indicated that the NS1 protein is a potential key factor for the different pathogenicity levels of the $\mathrm{H} 10$ avian influenza viruses in mink (Mustela vison) [27]. In this study, we applied an expression plasmid system carrying the ORF of NS1 of two avian influenza viruses, showing the difference in pathogenicity in mink [38]. Furthermore, these viruses represent different NS alleles, one from A ("mink/84") and the other one from B ("chicken/49"). A comparison of the predicted amino acid sequences of the two NS1 proteins showed 71 amino acid differences (Figure 3). However, the two NS1 proteins were found to be very similar regarding the previously identified important amino acid residues for the function of NS1 protein in the infected cells $[23,29,30,34,39,40]$.

Notably, the only difference was found in the site important for the NS1 protein's interaction with the 30 $\mathrm{kDa}$ subunit of cleavage and polyadenylation specificity factor (CPSF30) [27]. The NS1 protein interaction with the CPSF30 inhibits 3'-end processing of cellular premRNA $[29,30,34]$. This function is mediated by two distinct domains: one around residue 186 [30] and the other around residues 103 and 106 [41]. The NS1 protein of "mink/84" possessed the amino acid Glu186, Phe103 and Met106, whereas the NS1 protein of "chicken/49" possessed Tyr 103. A previous study [41] showed that mutations at the NS1 protein CPSF30 interaction sites dramatically changed the effect of the NS1 to control host gene expression.
Both "mink/84" and "chicken/49" NS1s had a negative effect on the activation of the ISRE promoter, as shown by the luciferase activity. But the reduction was much stronger in cells transfected with the "mink/84" NS1 plasmid with an average of $85.3 \%$ decrease in A549 cells (Figure 1A), whereas pNS-chicken/49 on average produced a $20.8 \%$ decrease in A549 cells. As this final product is dependent on both the induction of IFN and luciferase from the IFN receptor, the exact mechanism by which this interference is mediated through can be either by inhibiting IFN induction signals via RIG-I, MDA-5 or TRL-3, the processing of IFN mRNA, or the downstream effects via IFN receptor signalling or luciferase mRNA processing.

Several studies have indicated that the blocking of virus-induced IFN- $\beta$ promoter activation is mediated by the N-terminal RNA binding domain of the NS1 protein [42-44]. The 71 amino acid differences between the two NS1 proteins will most likely result in differences on the three-dimensional structure of the NS1 protein that could affect the function of NS1 in the suppression of IFN- $\beta$ promoter activation.

Since the induction of the IFN- $\beta$ promoter is associated with the production of IFN- $\beta$, we next investigated the level of endogenous IFN- $\beta$ mRNA and the amount of IFN- $\beta$ secreted in the cell supernatant. It has been observed that the NS1 protein of "mink/84" but not "chicken/49" strongly suppressed the expression of the IFN $-\beta$ gene and secretion of IFN- $\beta$ in the cell culture supernatant. In the time course study using A549 cells stimulated with poly I:C, IFN- $\beta$ production displayed three distinct phases. After an initial rapid increase it reached a peak and then declined to lower levels. The production of IFN $-\beta$ by poly I:C stimulation in A549 cells displayed a 2- to 4-hours lag followed by a steady increase in the accumulation of secreted IFN- $\beta$ in the cell culture media. Maximal yields were observed at 16 to 24 h post poly I:C stimulation (Figure $2 \mathrm{~A}$ ).

Similar observations were made when mRNA levels were measured. The expression during poly I:C stimulation revealed an early up regulation of IFN- $\beta$ transcripts starting at or before $2 \mathrm{~h}$ with a peak at 18-24 h after

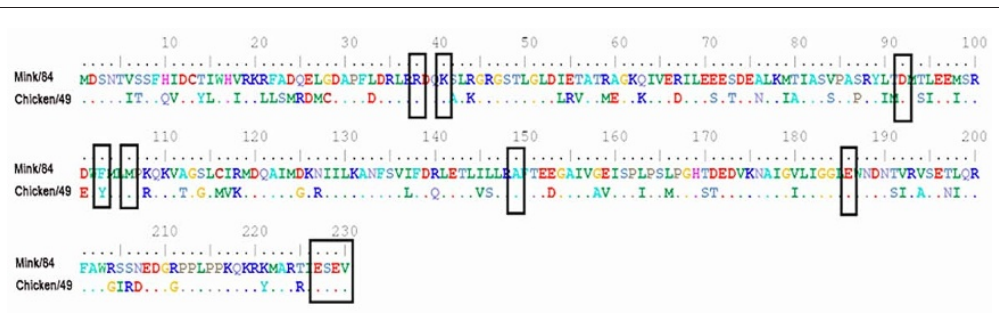

Figure 3 The predicted NS1 amino acid sequence alignments for the "mink/84" and "chicken/49" viruses. The boxes indicates the previously identified important amino acid residues for the function of NS1 protein in the infected cells. 
stimulation. During the first $4 \mathrm{~h}$ post-stimulation, we observed an up regulation of IFN- $\beta$ mRNA transcripts in A549 cells expressing the NS1 protein of "mink/84". Thereafter, the IFN- $\beta$ gene transcription was strongly suppressed, whereas a high level of the IFN $-\beta$ mRNA expression continued in A549 cells expressing NS1 protein of "chicken/49" (Figure 2B,C\&2D).

Future experiments are required to investigate the exact molecular mechanism behind this observation. This may require the use of animal experiments and also includes tools like reverse genetics, genomics and proteomic tools that allows the analysis of many parameters involved in the complex interplay between the NS1 and the host innate immune machinery.

\section{Conclusions}

All these observations indicate that different nonstructural protein 1 (NS1) of influenza viruses, one from allele A and another from allele B, show different abilities to suppress the induction of IFN mRNA; however, the exact mechanism is unknown. The results also demonstrate that the production of an important cytokine, IFN- $\beta$ is affected by the function of NS1 protein from different genetic gene pools.

It is possible that NS1 interacts with one of the inducing pathways, or both, or that the mRNA processing is blocked. The latter can be studied by investigating another inducible gene other than an IFN-dependent one.

\section{Methods}

After establishing an assay protocol for different part of our study, both NS1 construct were tested in duplicate at three independent experiments (each experiment was set up separately and carried out on different days).

\section{Construction of expression plasmids}

The NS1 open reading frames (ORF) of influenza A virus strains A/mink/Sweden/3900/84 ("mink/84") and A/chicken/Germany/N/49 ("chicken/49") were amplified using the primers NS1Kpn 5' (5'-ATTCGGTACCAGCAAAAGCAGGGTGACAAAG-3') and NS1XhoI 3' (5'TACCCTCGATAGAAACAAGGGTGTTTTTTAT-3'). Twenty-five microliter PCR-mix contained 1xPlatinum Taq buffer (Invitrogen), $200 \mu \mathrm{M}$ dNTP, $2.5 \mathrm{mM} \mathrm{MgCl}$, (Invitrogen) and $3 \mu \mathrm{l}$ cDNA. Reactions were placed in a thermal cycler at $95^{\circ} \mathrm{C}$ for $2 \mathrm{~min}$, then cycled 35 times between $95^{\circ} \mathrm{C} 20 \mathrm{sec}$, annealing at $58^{\circ} \mathrm{C}$ for $60 \mathrm{sec}$ and elongation at $72^{\circ} \mathrm{C}$ for $90 \mathrm{sec}$ and were finally kept at $8^{\circ}$ $\mathrm{C}$ until later use.

The 690 bp PCR products were digested with Kpn and $X h o I$ and cloned between the Kpn and XhoI sites of the mammalian expression vector pcDNA3.1 (Invitrogen, Carlsbad, CA, USA), creating pNS-mink/84 and pNS- chicken/49 plasmid respectively. The integrity of the plasmids was confirmed by sequencing.

\section{Cell culture and transfection experiments}

A549 cells, a type II alveolar epithelial cell line from human adenocarcinoma, (ATCC, CCL 185) were cultured in Dulbecco's modified Eagle medium (DMEM) and supplemented with $10 \%$ FCS in a humidified atmosphere of $5 \% \mathrm{CO}_{2}$ at $37^{\circ} \mathrm{C}$.

Transcriptional activity was assayed in the A549 cells. Cells were co-transfected with plasmids containing either the NS gene of "mink/84" or "chicken/49" together with reporter plasmids driving expression of Firefly luciferase (pISRE-TA-Luc) (Invitrogen) under the control of the IFN-stimulated response element (ISRE). The pRen-Luc plasmid containing the Renilla luciferase gene (Invitrogen) was used as internal control. The activity of the reporter gene were standardised by the Renilla luciferase activity. The inhibitory effect in cells expressing the various NS1s was expressed in folds of luciferase activity.

The transfection of the plasmids was conducted with FuGENE 6 reagent (Roche Molecular Biochemicals, Indianapolis, IN) in six-well plates according to the manufacturer's instructions. Initial experiments were conducted to optimise the efficiency of the transfection protocol. The day before transfection, cells were collected and seeded into six-well plates at $1 \times 10^{5}$ cells per well to achieve $70-80 \%$ confluence on the day of transfection. Each transfection group consisted of six wells in which three were poly I:C stimulated and three mock treated. Stimulation of the cells with the poly I:C was performed 24 hours after transfection of the pcDNA3.1/NS1 plasmid through the addition of $5 \mu \mathrm{g} /$ $\mathrm{ml}$ poly I:C mixed in $100 \mu \mathrm{l}$ DMEM without serum. Twenty-four hours later, the cells were harvested according to the protocol for the luciferase assay kit (Stratagene, Heidelberg, Germany), using $300 \mu \mathrm{l}$ lysis buffer for each well. Samples were kept on ice and centrifuged for $2 \mathrm{~min}$ at $14,000 \times g$ to remove cell debris before measurement of the luciferase activity. Luciferase activities were measured using $20 \mu \mathrm{l}$ of each sample according to the manufacturer's protocol.

\section{Western blot analysis}

All the transfections for western blot analysis were performed following the same protocol as described above. Briefly, cells were washed and lysed at 0, 2, 4, 8,16 and 24 hours post transfection using Bio-Plex cells lysis kit (Bio-Rad Laboratories, Hercules, CA) according to the manufacturer's instructions. After incubation for $20 \mathrm{~min}$ at $4^{\circ} \mathrm{C}$ and three times thawingfreezing steps at $-70^{\circ} \mathrm{C}$, the lysates were centrifuged at $4500 \mathrm{rpm}$ for $20 \mathrm{~min}$. Concentration and quality of 
the protein were measured using Nanodrop ND1000 (Nanodrop Technologies, Wilmington, DE.) and by SDS-polyacrylamide gel electrophoresis (SDS-PAGE) followed by Coomassie blue staining. A total of $50 \mu \mathrm{g}$ of the cell lysate was separated bySDS-PAGE in Ready Gel J 7.5\% (Bio-Rad) and then electronically transferred onto polyvinylidene difluoride (PVDF) membrane (GE Healthcare, Uppsala, Sweden). The membranes were incubated in blocking buffer (PBS, $2 \%$ (wt/vol) bovine serum albumin) at room temperature for one hour on slow agitation, the NS1and $\beta$ actin proteins were detected using anti-NS1 polyclonal, the NS1 antibodies was raised in goat against a peptide mapping near the C-terminus of influenza $\mathrm{A}$ NS1 (sc-17596, Santa Cruz Biothechnology, INC) and anti $\beta$-actin (Sigma-Aldrich, Stockholm, Sweden), followed by incubation with primary antibodies diluted in TBS-2\% BSA at $4^{\circ} \mathrm{C}$ overnight. After intensive washing with TBS (PBS, $0.2 \%$ Tween 20) membranes were incubated with horseradish peroxidase (HRP)conjugated anti-goat secondary antibodies for the NS1 and anti-mouse secondary antibodies for the $\beta$-actin detection for two hours at room temperature on continuous agitation. The blots were developed by an ECL advance kit from GE Healthcare and visualized in ChemDoc XRS system from Bio-Rad with Quantity One ${ }^{\oplus}$ software.

\section{Human IFN- $\beta$ ELISA}

The concentration of IFN- $\beta$ in stimulated A549 cell supernatants was determined using a commercially available VeriKine ${ }^{\mathrm{rw}}$ human IFN-beta sandwich enzymelinked immunosorbent assay (ELISA) kit (PBL interferon source, Piscataway, NJ, USA) according to the manufacturer's instructions. The cell supernatants were collected at $0,2,4,8,16,24$ and 48 hours post-poly I:C stimulations. Briefly, microtiter strips were incubated with 100 $\mu \mathrm{l}$ of IFN standards, blanks and samples. After one hour of incubation, the strips were washed and detection antibodies were added. After incubation and an additional washing step, streptavidin conjugated to horseradish peroxidase (HRP) was added, and the strips were incubated at room temperature for 1 hour. The strips were again washed before the addition of the tetramethyl benzidine (TMB) substrate solution, after which the strips were incubated for $15 \mathrm{~min}$ at room temperature in the dark. The reaction was terminated by the addition of stop solution, and the optical density of the wells was read at $450 \mathrm{~nm}$ using a microplate reader Multiscan EX (Thermo scientific, MA, USA). Values for the samples were compared to those for the standard curve and the amount of IFN- $\beta$ was estimated from the standard curve.

\section{Analysis of IFN- $\beta$ mRNA by RT-PCR}

RT-PCR was used to study the level of IFN $-\beta$ mRNA expression in Poly I:C-stimulated A549 cells. The housekeeping gene $\beta$-actin was used as a control. RT-PCR was performed using the following primer pairs specific to human IFN- $\beta$ and $\beta$-actin mRNA: IFN- $\beta$ forward 5' GGCCATGACCAACAAGTGTCTCCTCC 3' and reverse 5' ACAGGTTACCTCCGAAACTGAGCGC 3', resulting a product of $550 \mathrm{bp}$; and $\beta$-actin forward 5' TGGGTCAGAAGGACTCCTATG 3' and reverse 5' AGAAGAGCTATGAGCTGCCTG 3'. Twenty-five microliter PCR-mix contained 1xPlatinum Taq buffer (Invitrogen), $200 \mu \mathrm{M}$ dNTP, $2.5 \mathrm{mM} \mathrm{MgCl}_{2}$, (Invitrogen) and $3 \mu \mathrm{l}$ cDNA. Reactions were placed in a thermal cycler at $95^{\circ} \mathrm{C}$ for $2 \mathrm{~min}$, then cycled 35 times between $95^{\circ} \mathrm{C} 20 \mathrm{sec}$, annealing at $63^{\circ} \mathrm{C}$ for $60 \mathrm{sec}$ and elongation at $72^{\circ} \mathrm{C}$ for $90 \mathrm{sec}$ and were finally kept at $8^{\circ} \mathrm{C}$ until later use.

A549 cells were seeded in six-well plates and transfected with either pNS-mink/84, pNS-chicken/49 or empty pcDNA 3.1 vector as described above. Cells were stimulated with $5 \mu \mathrm{g} / \mathrm{ml}$ poly I:C mixed in $100 \mu \mathrm{l}$ DMEM without serum. Cells were harvested and RNA was extracted for RT-PCR assays at $0,4,8,16$ and 24 hours post-stimulation.

RNA was isolated using TRIzol Reagent (Invitrogen) according to the manufacturer's protocol. RNA was DNAse-treated and quantified and purity measured at $\mathrm{OD}_{260 / 280}$ using a Nanodrop ND1000 (Nanodrop Tec., Wilmington, DA, USA). All RNA samples had an $\mathrm{OD}_{260 / 280}$ ratio in water between 1.9 and 2.1. $2 \mu \mathrm{g}$ RNA was used to make cDNA templates using Superscript II (Invitrogen) according to the manufacturer's instructions and oligo-dT primers (Invitrogen).

\section{Acknowledgements}

The authors would like to gratefully acknowledge Professor Berndt Klingeborn for helpful scientific discussions and constant support. Our appreciation also goes to Dr. Lena Englund for her contributions to previous studies of the $\mathrm{H} 10$ viruses used in this study. This work was supported by the Swedish Research Council for the Environment, Agricultural Sciences and Spatial Planning (Formas Grants 159-2003-1824 and 221-2007-935).

\section{Author details}

'Swedish University of Agricultural Sciences (SLU), Department of Biomedical Sciences and Veterinary Public Health, Section of Virology, SLU, Ulls väg 2B, SE-751 89 Uppsala, Sweden. ${ }^{2}$ Department of Virology, Immunobiology and Parasitology, National Veterinary Institute (SVA), Ulls väg 2B, SE-751 89 Uppsala, Sweden.

\section{Authors' contributions}

SZ conceived and designed the study, organized protocol developments, performed the transfection-, real-time RT-PCR, western blotting and ELISA analyses, contributed to interpretation of data and wrote the manuscript. MM, organized protocol developments, contributed to the interpretation of the findings and revised the manuscript. GM , contributed to and revised the manuscript. SB contributed to conception, interpretation of data, and revised the manuscript. $\mathrm{MB}$ additionally contributed to the study design, 
contributed to conception, interpretation of data and revised the manuscript. All authors' have read and approved the final manuscript.

\section{Competing interests}

The authors declare that they have no competing interests.

Received: 5 October 2010 Accepted: 31 December 2010 Published: 31 December 2010

\section{References}

1. Haller O, Kochs G, Weber F: The interferon response circuit: Induction and suppression by pathogenic viruses. Virology 2006, 344:119-130.

2. Takeuchi O, Akira S: Recognition of viruses by innate immunity. Immunological Reviews 2007, 220:214-224.

3. Der SD, Zhou A, Williams BRG, Silverman RH: Identification of genes differentially regulated by interferon $a, b$, or $g$ using oligonucleotide arrays. Proc Natl Acad Sci USA 1998, 95:15623-15628.

4. Samuel CE: Antiviral actions of interferons. Clin Microbiol Rev 2001, 14:778-809.

5. Hornung V, Ellegast J, Kim S, Brzozka K, Jung A, Kato H, Poeck H, Akira S, Conzelmann KK, Schlee M, et al: 5'-Triphosphate RNA is the ligand for RIG-I. Science 2006, 314:994-997.

6. Kato H, Takeuchi O, Sato S, Yoneyama M, Yamamoto M, Matsui K, Uematsu S, Jung A, Kawai T, Ishii KJ, et al: Differential roles of MDA5 and RIG-I helicases in the recognition of RNA viruses. Nature 2006 441:101-105.

7. Kawai T, Akira S: Innate immune recognition of viral infection. Nat Immunol 2006, 7:131-137.

8. Pichlmair A, Schulz O, Tan CP, Naslund TI, Liljestrom P, Weber F, Reis e Sousa C: RIG-I-mediated antiviral responses to single-stranded RNA bearing 5'-phosphates. Science 2006, 314:997-1001.

9. Yoneyama M, Kikuchi M, Natsukawa T, Shinobu N, Imaizumi T, Miyagishi M, Taira K, Akira S, Fujita T: The RNA helicase RIG-I has an essential function in double-stranded RNA-induced innate antiviral responses. Nat Immunol 2004, 5:730-737.

10. Alexopoulou L, Holt AC, Medzhitov R, Flavell RA: Recognition of doublestranded RNA and activation of NF-kappaB by Toll-like receptor 3. Nature 2001, 413:732-738

11. Sen GC: VIRUSES AND INTERFERONS. Annual Review of Microbiology 2001, 55:255-281.

12. Tortorella D, Gewurz BE, Furman MH, Schust DJ, Ploegh HL: VIRAL SUBVERSION OF THE IMMUNE SYSTEM. Annu Rev Immunol 2000 18:861-926.

13. Garcia-Sastre A: Inhibition of Interferon-Mediated Antiviral Responses by Influenza A Viruses and Other Negative-Strand RNA Viruses. Virology 2001, 279:375-384

14. Hale BG, Randall RE, Ortin J, Jackson D: The multifunctional NS1 protein of influenza A viruses. J Gen Virol 2008, 89:2359-2376.

15. Hatada E, Saito S, Fukuda R: Mutant influenza viruses with a defective NS1 protein cannot block the activation of PKR in infected cells. J Virol 1999, 73:2425-2433.

16. Lu Y, Wambach M, Katze MG, Krug RM: Binding of the influenza virus NS1 protein to double-stranded RNA inhibits the activation of the protein kinase that phosphorylates the elF-2 translation initiation factor. Virology 1995, 214:222-228

17. Lamb RA, Choppin PW: Segment 8 of the Influenza Virus Genome is Unique in Coding for Two Polypeptides. Proceedings of the National Academy of Sciences 1979, 76:4908-4912.

18. Inglis SC, Barrett T, Brown CM, Almond JW: The Smallest Genome RNA Segment of Influenza Virus Contains Two Genes that May Overlap. Proceedings of the National Academy of Sciences 1979, 76:3790-3794.

19. Krug RM, Yuan W, Noah DL, Latham AG: Intracellular warfare between human influenza viruses and human cells: the roles of the viral NS1 protein. Virology 2003, 309:181-189.

20. Talon J, Horvath CM, Polley R, Basler CF, Muster T, Palese P, Garcia-Sastre A: Activation of interferon regulatory factor 3 is inhibited by the influenza A virus NS1 protein. Journal Of Virology 2000, 74:7989-7996.
21. Bergmann M, Garcia-Sastre A, Carnero E, Pehamberger H, Wolff K, Palese $P$, Muster T: Influenza virus NS1 protein counteracts PKR-mediated inhibition of replication. Journal Of Virology 2000, 74:6203-6206.

22. Li S, Min JY, Krug RM, Sen GC: Binding of the influenza A virus NS1 protein to PKR mediates the inhibition of its activation by either PACT or double-stranded RNA. Virology 2006, 349:13-21.

23. Min JY, Krug RM: The primary function of RNA binding by the influenza A virus NS1 protein in infected cells: Inhibiting the $2^{\prime}-5^{\prime}$ oligo (A) synthetase/RNase $L$ pathway. Proceedings of the National Academy of Sciences 2006, 103:7100-7105.

24. Ludwig S, Schultz U, Mandler J, Fitch WM, Scholtissek C: Phylogenetic relationship of the nonstructural (NS) genes of influenza $A$ viruses. Virology 1991, 183:566-577.

25. Suarez $\mathrm{DL}$, Perdue ML: Multiple alignment comparison of the nonstructural genes of influenza A viruses. Virus Research 1998, 54:59-69.

26. Chen GW, Chang SC, Mok CK, Lo YL, Kung YN, Huang JH, Shih YH, Wang JY, Chiang C, Chen CJ, Shih SR: Genomic signatures of human versus avian influenza A viruses. Emerg Infect Dis 2006, 12:1353-1360.

27. Zohari S, Metreveli G, Kiss I, Belak S, Berg M: Full genome comparison and characterization of avian $\mathrm{H} 10$ viruses with different pathogenicity in Mink (Mustela vison) reveals genetic and functional differences in the non-structural gene. Virology journal 2010, 7:145

28. Stark GR, Kerr IM, Williams BR, Silverman RH, Schreiber RD: How cells respond to interferons. Annu Rev Biochem 1998, 67:227-264.

29. Chen Z, Li Y, Krug R: Influenza A virus NS1 protein targets poly(A)binding protein II of the cellular 3 '-end processing machinery. EMBO J 1999, 18:2273-2283.

30. Li Y, Chen ZY, Wang W, Baker CC, Krug RM: The 3'-end-processing factor CPSF is required for the splicing of single-intron pre-mRNAs in vivo. RNA 2001, 7:920-931.

31. Lamb RA, Lai CJ: Sequence of interrupted and uninterrupted mRNAs and cloned DNA coding for the two overlapping nonstructural proteins of influenza virus. Cell 1980, 21:475-485.

32. Qiu Y, Krug RM: The influenza virus NS1 protein is a poly(A)-binding protein that inhibits nuclear export of mRNAs containing poly(A). J Virol 1994, 68:2425-2432.

33. Satterly N, Tsai PL, van Deursen J, Nussenzveig DR, Wang Y, Faria PA, Levay A, Levy DE, Fontoura BMA: Influenza virus targets the mRNA export machinery and the nuclear pore complex. Proceedings of the National Academy of Sciences 2007, 104:1853-1858.

34. Nemeroff ME, Barabino SML, Li Y, Keller W, Krug RM: Influenza Virus NS1 Protein Interacts with the Cellular $30 \mathrm{kDa}$ Subunit of CPSF and Inhibits 3' End Formation of Cellular Pre-mRNAs. Molecular Cell 1998, 1:991-1000.

35. Aragon T, de la Luna S, Novoa I, Carrasco L, Ortin J, Nieto A: Eukaryotic Translation Initiation Factor 4GI Is a Cellular Target for NS1 Protein, a Translational Activator of Influenza Virus. Mol Cell Biol 2000, 20:6259-6268.

36. Bucher $E$, Hemmes $H$, de Haan $P$, Goldbach $R$, Prins M: The influenza A virus NS1 protein binds small interfering RNAs and suppresses RNA silencing in plants. J Gen Virol 2004, 85:983-991.

37. Mibayashi M, Martinez-Sobrido L, Loo YM, Cardenas WB, Gale M Jr, GarciaSastre A: Inhibition of Retinoic Acid-Inducible Gene I-Mediated Induction of Beta Interferon by the NS1 Protein of Influenza A Virus. J Virol 2007, 81:514-524.

38. Berg $M$, Englund $L$, Abusugra $\mid A$, Klingeborn $B$, Linné $T$ : Close relationship between mink influenza (H10N4) and concomitantly circulating avian influenza viruses. Arch Virol 1990, 113:61-71.

39. Wang W, Riedel K, Lynch P, Chien CY, Montelione GT, Krug RM: RNA binding by the novel helical domain of the influenza virus NS1 protein requires its dimer structure and a small number of specific basic amino acids. RNA 1999, 5:195-205

40. Li Z, Jiang $Y$, Jiao $P$, Wang $A$, Zhao F, Tian G, Wang $X, Y u$ K, Bu Z, Chen H: The NS1 Gene Contributes to the Virulence of H5N1 Avian Influenza Viruses. J Virol 2006, 80:11115-11123.

41. Kochs G, Garcia-Sastre A, Martinez-Sobrido L: Multiple Anti-Interferon Actions of the Influenza A Virus NS1 Protein. J Virol 2007, 81:7011-7021.

42. Donelan NR, Basler CF, Garcia-Sastre A: A recombinant influenza A virus expressing an RNA-binding-defective NS1 protein induces high levels of beta interferon and is attenuated in mice. J Virol 2003, 77:13257-13266. 
43. Guo Z, Chen L-m, Zeng H, Gomez JA, Plowden J, Fujita T, Katz JM, Donis RO, Sambhara S: NS1 Protein of Influenza A Virus Inhibits the Function of Intracytoplasmic Pathogen Sensor, RIG-I. Am J Respir Cell Mol Biol 2006, 36:263-269.

44. Hayman A, Comely S, Lackenby A, Murphy S, McCauley J, Goodbourn S, Barclay W: Variation in the ability of human influenza A viruses to induce and inhibit the IFN-[beta] pathway. Virology 2006, 347:52-64.

doi:10.1186/1743-422X-7-376

Cite this article as: Zohari et al:: Differences in the ability to suppress interferon $\beta$ production between allele A and allele B NS1 proteins from H10 influenza A viruses. Virology Journal 2010 7:376.

Submit your next manuscript to BioMed Central and take full advantage of:

- Convenient online submission

- Thorough peer review

- No space constraints or color figure charges

- Immediate publication on acceptance

- Inclusion in PubMed, CAS, Scopus and Google Scholar

- Research which is freely available for redistribution

Submit your manuscript at www.biomedcentral.com/submit
() Biomed Central 